\title{
Cerebral microbleeds: from depiction to interpretation
}

\author{
Laurent Puy (1), ${ }^{1}$ Marco Pasi, ${ }^{1}$ Mark Rodrigues 다, ${ }^{2}$ Susanne J van Veluw, ${ }^{3}$ \\ Georgios Tsivgoulis (1) , ${ }^{4}$ Ashkan Shoamanesh, ${ }^{5}$ Charlotte Cordonnier ${ }^{1}$
}

\begin{abstract}
- Additional material is published online only. To view, please visit the journal online (http://dx.doi.org/10.1136/ jnnp-2020-323951).

'Department of Neurology, U1172 - LilNCog - Lille

Neuroscience \& Cognition, Univ. Lille, Inserm, CHU Lille, F-59000

Lille, France

${ }^{2}$ Centre for Clinical Brain Sciences, The University of Edinburgh College of Medicine and Veterinary Medicine, Edinburgh, UK

${ }^{3}$ Neurology Department Hemorrhagic Stroke Research Program, Department of Neurology, Massachusetts General Hospital Stroke Research Center, Harvard Medical School, Boston, Massachusetts, USA

${ }^{4}$ Second Department of Neurology, "Attikon" University Hospital, National and Kapodistrian University of Athens, School of Medicine, Athens, Greece

${ }^{5}$ Department of Medicine (Neurology), McMaster University and Population Health Research Institute, Hamilton, Ontario, Canada
\end{abstract}

\section{Correspondence to} Dr Charlotte Cordonnier, Lille University Hospital Center, 59000 Lille, Hauts-de-France, France; charlotte.cordonnier@ univ-lille.fr

Received 6 October 2020 Revised 22 December 2020 Accepted 4 January 2021 Published Online First 9 February 2021

Check for updates

(C) Author(s) (or their employer(s)) 2021. No commercial re-use. See rights and permissions. Published by BMJ.

To cite: Puy L, Pasi $\mathrm{M}_{\text {, }}$ Rodrigues M, et al. I Neurol Neurosurg Psychiatry 2021:92:598-607.

\section{ABSTRACT}

Cerebral microbleeds (CMBs) are defined as hypointense foci visible on $\mathrm{T} 2^{*}$-weighted and susceptible-weighted MRI sequences. CMBs are increasingly recognised with the widespread use of MRI in healthy individuals as well as in the context of cerebrovascular disease or dementia. They can also be encountered in major critical medical conditions such as in patients requiring extracorporeal mechanical oxygenation. The advent of MRI-guided postmortem neuropathological examinations confirmed that, in the context of cerebrovascular disease, the vast majority of CMBs correspond to recent or old microhaemorrhages. Detection of CMBs is highly influenced by MRI parameters, in particular field strength, postprocessing methods used to enhance T2* contrast and three dimensional sequences. Despite recent progress, harmonising imaging parameters across research studies remains necessary to improve crossstudy comparisons. CMBs are helpful markers to identify the nature and the severity of the underlying chronic small vessel disease. In daily clinical practice, presence and numbers of CMBs often trigger uncertainty for clinicians especially when antithrombotic treatments and acute reperfusion therapies are discussed. In the present review, we discuss those clinical dilemmas and address the value of CMBs as diagnostic and prognostic markers for future vascular events.

\section{INTRODUCTION}

Cerebral microbleeds (CMBs) are a radiological construct and appear as hypointense foci visible only on MRI. ${ }^{1}$ CMBs have received increasing interest over the past two decades. They can be observed in individuals with stroke and cognitive complaints and in healthy individuals. In daily clinical practice, the presence and numbers of CMBs often trigger uncertainty for clinicians especially when antithrombotic treatments are considered.

In this review, we will critically analyse the knowledge accumulated and advances about CMBs and will focus our discussion on the nature of these MRI-defined lesions, their potential role as diagnostic and prognostic markers, and when and how CMBs should influence our management.

\section{CMBS ARE RADIOLOGICAL CONSTRUCTS, BUT} WHAT IS THEIR HISTOPATHOLOGICAL NATURE? Cerebral MRI: from image acquisition to image analysis

CMBs are small $(2-10 \mathrm{~mm}$ diameter) round or ovoid hypointense foci with associated blooming with enhanced visibility on MRI sequences sensitive to susceptibility effects. ${ }^{23}$

\section{Image acquisition parameters}

Local magnetic field inhomogeneities caused by paramagnetic iron in CMBs result in signal loss on some MRI sequences. T2*-weighted gradient echo, usually acquired as two-dimensional axial images with $3-5 \mathrm{~mm}$ slice thickness at $1.5 \mathrm{~T}$, is the traditional sequence used to detect CMBs but several parameters can influence their depiction (figure 1). ${ }^{2}$ A low flip angle, long echo time and long repetition time increase the sensitivity to susceptibility effects. ${ }^{2}$ The susceptibility effect and signal-to-noise ratio increase with higher magnetic field strength (eg, $3 \mathrm{~T}$ or $7 \mathrm{~T}$ compared with 1.5 $\mathrm{T}) .{ }^{4-8}$ Increasing the spatial resolution by acquiring three dimensional sequences improves $\mathrm{CMB}$ detection. ${ }^{5}$ Susceptibility-weighted imaging (SWI) is derived from gradient echo pulse sequences with additional postprocessing steps to improve contrast resolution. It is usually acquired in three dimensions to increase spatial resolution and has flow compensation in all three planes to reduce artefacts. SWI has increased sensitivity and reliability for CMBs compared with $\mathrm{T} 2 *$-weighted gradient echo but requires longer acquisition time. ${ }^{9}$ Fast acquisition of SWI using a parallel imaging technique results may improve detection. ${ }^{10}$

\section{Image analysis}

Some structures or lesions exhibit susceptibility effects that can mimic CMBs (eg, curvilinear small cortical vessels, iron deposits in the basal ganglia, diamagnetic calcifications and artefact from bone-air interfaces in the temporal and inferior frontal lobes) and must be excluded first. CMBs are most frequently identified and quantified using visual assessment. The Microbleed Anatomical Rating Scale and Brain Observer MicroBleed Scale provide structured approaches for assessing CMBs. ${ }^{11} 12$ These scales have been developed using T2*-weighted GRE at $1.5 \mathrm{~T}$ but less is known about inter-rater agreement using SWI and at higher field strengths. Semiautomated and fully automated approaches are potentially useful for quantifying CMBs given the time required and inter-rater variability of visual rating. Several methods have been described using lesion intensity and/or geometry to detect CMBs, resulting in sensitivities for CMBs ranging from $50 \%$ to $89 \% .{ }^{13-15}$ However, the small size of CMBs, their potential mimics and anatomical distortions due to background brain lesions (such as macrohaemorrhages or tumours) limit specificity, resulting in many false positives that need to be removed by visual inspection. Machinelearning methods may minimise the number of false 

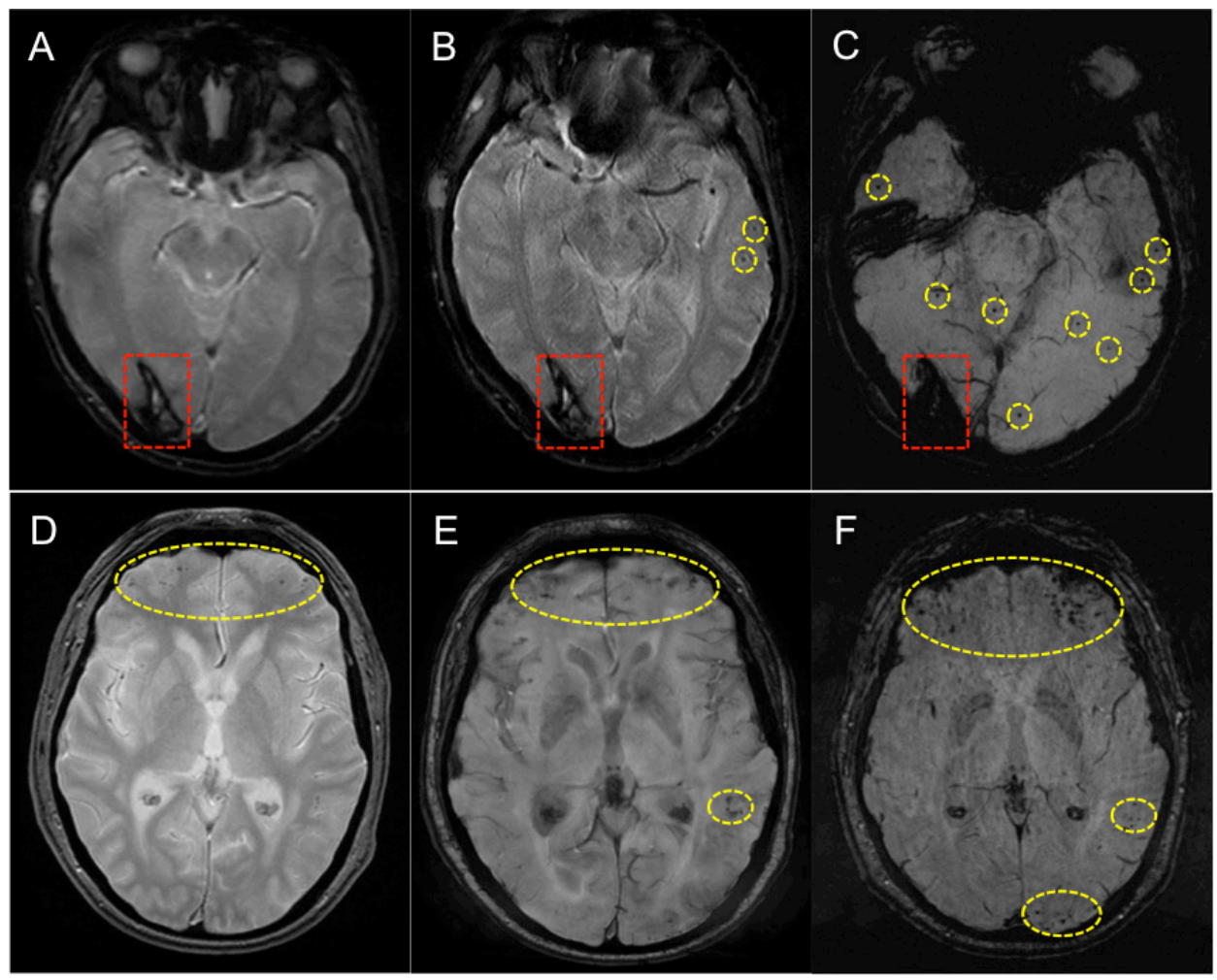

Figure 1 Influence of sequence and magnetic field strength on CMB detection. Effects of sequence and magnetic field strength on CMB detection in two patients with spontaneous intracerebral haemorrhage (A-C and D-F). (A) Axial T2* -gradient echo at $1.5 \mathrm{~T}$ shows a right occipital intracerebral haemorrhage (red rectangle) but no CMBs, (B) axial SWI at 1.5 T shows two left temporal CMBs (yellow rings) and (C) axial minimum intensity projection SWI at $3 \mathrm{~T}$ shows multiple CMBs in the temporal and occipital lobes and cerebellar vermis (yellow rings). (D) Axial T2* ${ }^{*}$ gradient echo at $1.5 \mathrm{~T}$ shows a few CMBs in both frontal lobes and the left temporal lobe (yellow rings), (E) axial SWI at 1.5 T shows more CMBs in the frontal and left temporal lobes plus left occipital lobe CMBs (yellow rings) and (F) axial SWI at 3 T shows more CMBs with increased conspicuity in the frontal and left occipital lobes (yellow rings). CMB, cerebral microbleed; SWI, susceptibility-weighted imaging.

positives using high-level features. ${ }^{16}$ However, such methods are challenging since they need large precisely labelled data sets for training and a large number of participants with varying underlying pathologies imaged on different MRI systems.

\section{Recent advances and novel approaches}

Ultra-high field $7 \mathrm{~T}$ MRI is a promising technique for studying CMBs. 7 T MRI detects more CMBs than $3 \mathrm{~T}$ or $1.5 \mathrm{~T}$, particularly smaller CMBs. ${ }^{6}$ The high spatial resolution of 7 T MRI allows detailed assessment of CMBs as well as microvessels structure and function, which may help establish a pathophysiological link between CMBs and small vessel diseases (SVDs). However, the increased artefacts at 7 T MRI, especially near the skull base, may hinder its use. Quantitative susceptibility mapping (QSM) permits quantitative measures of tissue susceptibility, such as iron and calcium, using GRE phase data. ${ }^{17}$ The total magnetic susceptibility of a CMB is relatively consistent across imaging parameters ${ }^{18}$ and independent of field strength.Therefore, QSM may provide a more consistent method for quantifying CMB burden within and across studies, and detecting longitudinal change than assessing their number on T2*-weighted GRE or SWI. ${ }^{4}$

\section{Histopathological correlates and mechanisms of brain injury} Understanding of the histopathological correlates of CMBs was initially lacking. The advent of MRI-guided neuropathological examinations, in the context of cerebrovascular diseases, helped bridge this gap, confirming that the majority of CMBs correspond to recent or old microhaemorrhages. ${ }^{19} 20$ Recent microhaemorrhages can be identified by intact or lysed extravasated red blood cells on standard H\&E-stained sections. In the subacute phase ( $>24$ hours after extravasation) red blood cells lyse and are transformed into blood-breakdown products in the form of haematoidin or haemosiderin and are taken up by macrophages (figure 2). Chronic microhaemorrhages can be identified by focal clusters of haemosiderin-laden macrophages on H\&E that stain positive for iron. The presence of iron in old microhaemorrhages contributes to enhanced visibility on MRI. ${ }^{20-22}$ A combined in vivo MRI-ex vivo MRI-histopathology study in cases with cerebral amyloid angiopathy (CAA) revealed that due to this 'blooming effect' lesions that measured only a few hundred $\mu \mathrm{m}$ on H\&E were still detectable on T2*-weighted clinical in vivo MRI. ${ }^{21}$ That said, conventional MRI routinely used in clinical practice likely underestimates total CMB burden. ${ }^{212324}$ Other lesions, such as microaneurysms, fibrinoid necrosis and haemorrhagic microinfarcts are thought to account for a small subset of MRI-detected CMBs ${ }^{20} 21$ (figure 2).

Besides an increased understanding of the histopathological correlates of MRI-observed CMBs, ex vivo MRI-guided histopathological evaluation of CMBs has provided clues for their potential pathophysiological mechanisms. In patients with sporadic CAA, CMBs are almost exclusively found in the cortical grey matter, predominantly in posterior brain regions where CAA is often more severe. ${ }^{25}$ Serial sectioning of individual CMBs revealed that the majority originate from penetrating cortical arterioles and are the result of advanced CAA. Interestingly, 


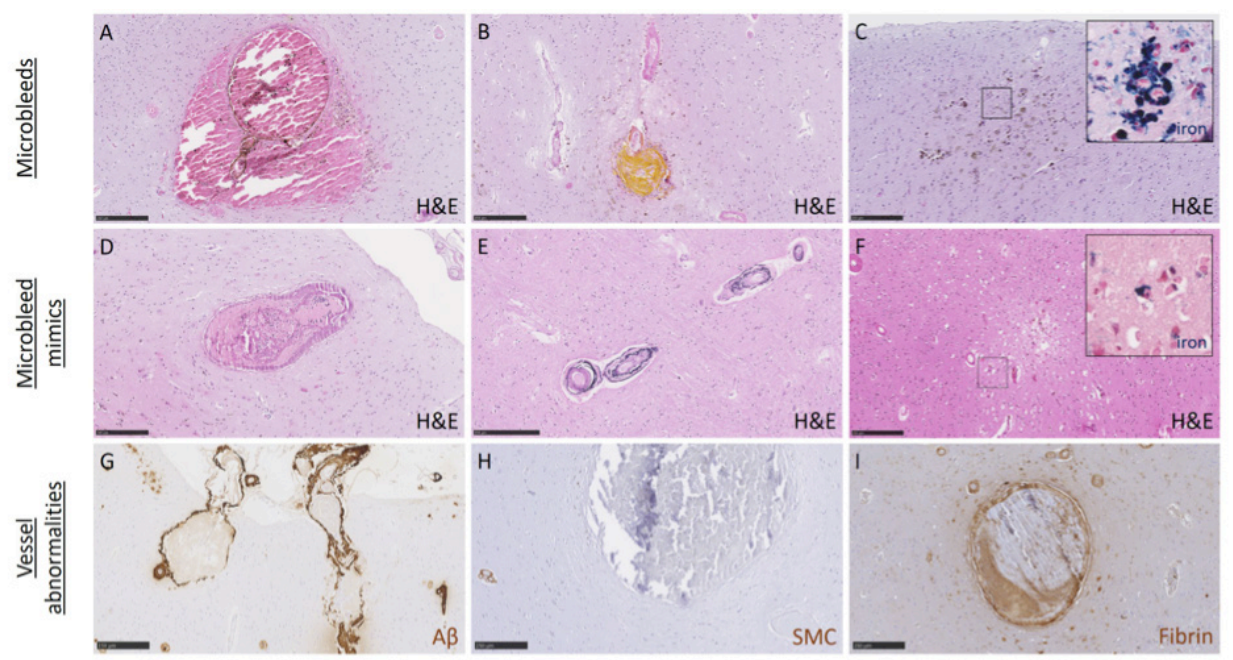

Figure 2 Histopathological examples of cerebral microbleeds (CMBs), mimics and associated vessel abnormalities. Examples of acute (A), subacute (B), and an iron-positive old microbleed (C) on H\&E-stained sections in cases with cerebral amyloid angiopathy (CAA). Examples of fibrinoid necrosis (D), vessel calcifications (E), and an iron-positive haemorrhagic microinfarct (F) that can appear as microbleeds on T2* -weighted MRI. Examples of vessel abnormalities that have been associated with microbleed formation include fragmentation of the wall including loss of amyloid $\beta$ (A $\beta$ ) in a case with CAA (G), loss of smooth muscle cells (SMCS) in a case with hypertensive arteriopathy $(\mathrm{H})$, and fibrin extravasation into the wall and surrounding parenchyma (I). All scale bars indicate $250 \mu \mathrm{m}$.

vessels involved in microbleeding had an abnormal appearance, including dilation and fragmentation of the wall, loss of both smooth muscle cells and amyloid $\beta$ (A $\beta$ ), and fibrin extravasation. ${ }^{25}{ }^{26}$ Collectively, these histopathological findings suggest that CAA-affected blood vessels may undergo extensive remodelling prior to bleeding. Whether this process is in part immunemediated is currently under investigation and has implications for the interpretation of haemorrhagic amyloid-related imaging abnormalities in the context of anti-A $\beta$ immunotherapy. ${ }^{27}$ Whether similar pathophysiological mechanisms play a role in the formation of CMBs in deeper areas of the brain in cases with hypertensive arteriopathy is currently incompletely understood and awaits further (preferably MRI-guided) histopathological investigations. $^{2829}$

Experimental animal models of CMBs provide further information on their formation and impact on brain function. CMBs can be induced either as individual (eg, collagenase microinjection, laser-irradiation) or disseminated lesions (eg, stroke prone and CAA models, cyclodextrin nanoparticles injection, lipopolysaccharides injections and specific diet models inducing hyperhomocysteinaemia). While CMBs do not exert immediate mechanical mass effect on adjacent tissue ${ }^{30}{ }^{31}$ they trigger an early and persistent periOlesional microgliosis and astrogliosis, responsible for delayed dendrite degeneration and neuronal death. ${ }^{32-34}$ These secondary brain damages are mediated by the leakage of blood-derived molecules in the parenchyma that promote inflammation and are indirectly responsible for delayed neuronal toxicity. ${ }^{35}$

\section{CMBS IN DAILY PRACTICE}

CMB location as marker of the nature of underlying SVD

$\mathrm{CMBs}$ are helpful to evaluate the underlying microangiopathy and its severity. ${ }^{36}{ }^{37}$ The spatial distribution of CMBs tends to parallel the different anatomical distribution of CAA (mainly affecting cortical and leptomeningeal vessels) and vascular risk factors-related degenerative small vessel changes (ie, arteriolosclerosis that mainly involves the vasculature supplying the supratentorial deep grey nuclei and white matter), and is thus considered a useful MRI biomarker to differentiate these two main forms of sporadic SVD (figure 3). ${ }^{2} 3638$ Strictly lobar $\mathrm{CMBs}$ are used for CAA diagnosis within the modified Boston criteria. ${ }^{36}$ They have a high positive predictive value for CAA even in individuals without spontaneous intracerebral haemorrhage $(\mathrm{sICH})$ presentations in a hospital-based setting (specificity $90 \%) .{ }^{39}$ However, in the absence of an appropriate clinical context (ie, sICH, convexity subarachnoid haemorrhage, transient focal neurological episodes and cognitive impairment) the overall specificity is low, as lobar CMBs can be found also in the absence of CAA. ${ }^{39}$ An international collaboration is underway to update and improve the diagnostic test accuracy of the Boston criteria for CAA and provide external validation of the criteria in a large sample. ${ }^{40}$

In the appropriate clinical context (ie, sICH, lacunar stroke, cognitive impairment), strictly deep CMBs are generally thought to be associated with hypertension-related SVD (ie, arteriolosclerosis). ${ }^{38}$ However in this context, to date no studies have evaluated the diagnostic performance of deep CMBs for the presence of underlying arteriolosclerosis.

Patients with mixed CMBs are of interest since they may exhibit the presence of a severe and diffuse form of arteriolosclerosis or the combination of both CAA and arteriolosclerosis, especially in the elderly. ${ }^{374} 42$ In this context, an underlying hereditary SVD (eg, CADASIL) ${ }^{43}$ should also be considered, especially in younger patients and if other relevant clinical and radiological features coexist.

The cerebellum may be affected by both types of SVD. In the sICH population, preliminary results suggest that cerebellar $\mathrm{CMBs}$ are a frequent finding (44\%) and as in supratentorial CMBs they show different distribution patterns (strictly superficial vs deep/mixed cerebellar pattern) (figure 3$) \cdot{ }^{44}$ Amyloid positron emission tomography (PET) may provide insights into the pathophysiology of CMBs. Pathology and Pittsburgh compound-B PET-based findings suggest that patients with sICH who harbour CAA as the dominant SVD type mainly show cerebellar CMBs restricted to the superficial cerebellar regions. ${ }^{445}$ 


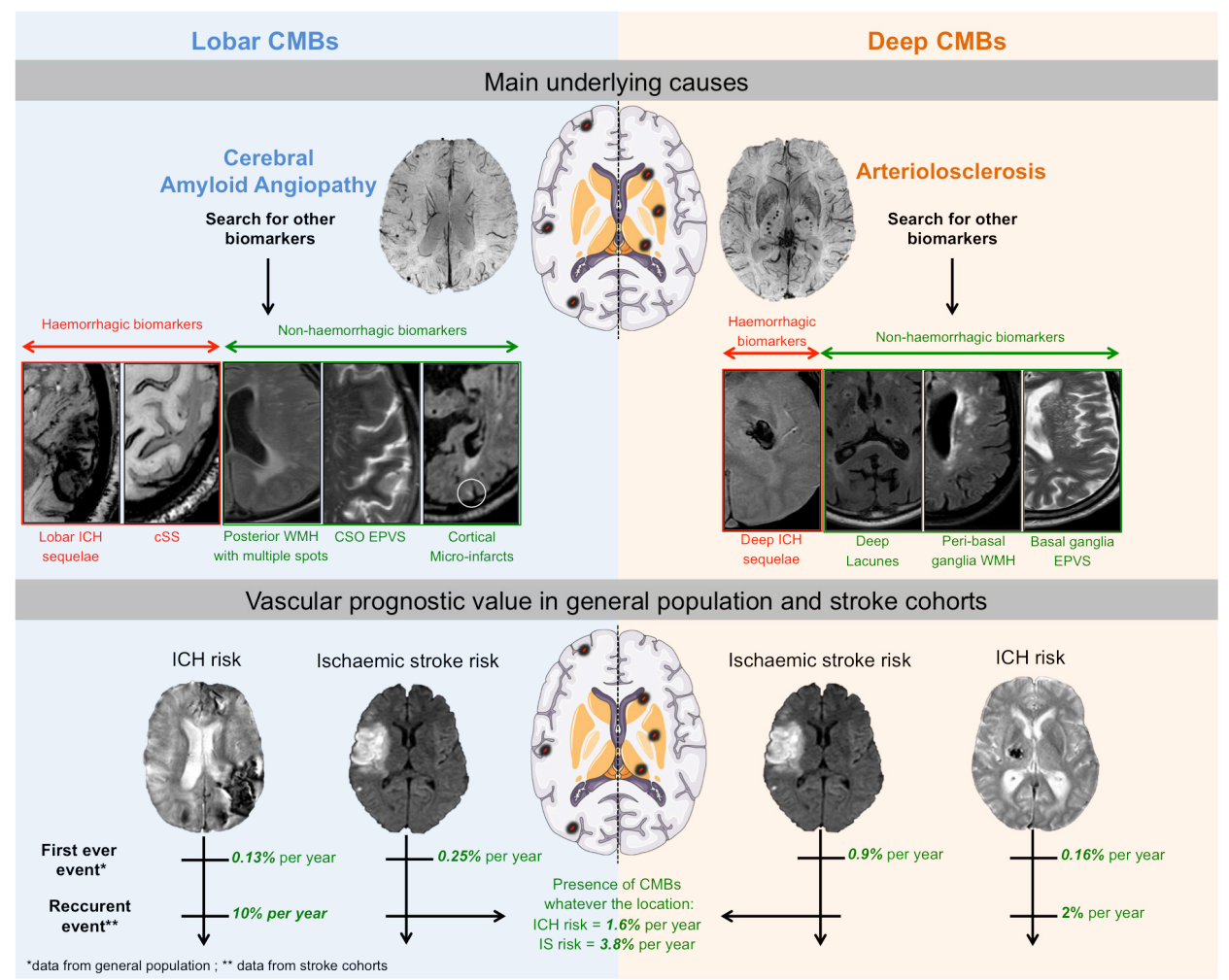

Figure 3 Lobar CMBs and deep CMBs share distinct underlying causes and stroke risks. CMBs, cerebral microbleeds; CSO, centrum semi-ovale; CSS, cortical superficial siderosis; EPVS, enlarged perivascular spaces; ICH, intracerebral haemorrhage; IS, ischaemic stroke; WMH, white matter hyperintensities. Estimated risks of first ever strokes and recurrent strokes are adapted from general population based studies and stroke cohorts, respectively (adapted from Akoudad et al, Charidimou et al, Charidimou et al and Imaizumi et al). ${ }^{4964-66}$

CMB prevalence and progression in healthy elderly people Reported prevalences of CMBs in elderly populations mainly vary according to the mean age of the population, and according to neuroimaging parameters. CMBs are relatively common in older individuals ranging from $5 \%$ to $35 \%$ in large populationbased studies ${ }^{46-49}$ and cumulative incidences of new CMBs of approximately $7 \%-10 \%$ over a period of $3-4$ years. ${ }^{50}{ }^{51}$ The reported location of CMBs was predominantly lobar ranging from 48\% in the Northern Manhattan Study to 70\% in the Age, Gene/Environment Susceptibility-Reykjavik Study. ${ }^{46}{ }^{47}$ Deep (ie, basal ganglia, thalami, deep white matter and infratentorial location) and mixed location CMBs (ie, lobar and deep) ranged from $32 \%$ in the Rotterdam Scan Study ${ }^{48}$ to $52 \%$ in the Northern Manhattan Study. ${ }^{47}$ Risk factors for CMBs in elderly populations largely differ according to the location of CMBs suggesting different underlying microangiopathies. Lobar CMBs are consistently associated with APOE status ( $\varepsilon 4$ and $\varepsilon 2)$ suggesting an association with CAA, even in elderly individuals without neurological disease. ${ }^{52}$

\section{CMB prevalence and progression in patients who had a stroke}

Patients with ischaemic stroke (IS) or sICH typically show higher prevalence and number of CMBs than stroke-free populations in part because they share a higher burden of vascular risk factors. $\mathrm{CMBs}$ are frequent among patients with sICH with an estimated prevalence of $60 \%{ }^{53}$ and a recent meta-analysis reports that incident CMBs occur in approximately $40 \%$ of patients during a mean 27 months of follow-up after sICH. ${ }^{54}$ Presence and number of CMBs at baseline have been consistently reported as strong predictors of incident CMBs. ${ }^{5455}$ In the context of IS, one patient out of three has at least one CMB..$^{53}$ In such populations, around $5 \%$ of patients exhibit five or more CMBs. ${ }^{5657} \mathrm{CMB}$ prevalence is also particularly high in patients with genetic diseases of small blood vessels (eg, CADASIL, ${ }^{58}$ CARASIL, ${ }^{59}$ hereditary Dutch type CAA,${ }^{60}$ COL4A1 mutations ${ }^{61}$ or other vascular conditions (eg, Moyamoya disease) ${ }^{62}$ and Fabry disease ${ }^{63}$.)

\section{CMBs are prognostic markers of both haemorrhagic and ischaemic risks}

CMBs are key markers of cerebrovascular risk, which vary according to their location and subgroup populations (figure 3).

In stroke-free individuals, the overall presence of CMBs is associated with a 5.5 -fold and 2-fold increased risk of first $\mathrm{sICH}$ and first IS, respectively. ${ }^{64}$ Interestingly the location of CMBs is important: while lobar CMBs are associated with a fivefold increased risk of sICH, it does not seem to influence the IS risk. In contrast, deep CMBs are associated with a 6-fold increased risk of sICH and a 2.5 -fold increased risk of IS. ${ }^{49}$

In patients with a history of sICH, the risk of recurrence depends on both the location of ICH and CMBs. After a lobar sICH, the presence of CMBs (whatever their location) quadruples the risk of recurrence. ${ }^{65}$ Annual risk of sICH recurrence is lower in patients with mixed (both lobar and deep) sICH and CMBs $(5.1 \%$ per year), and deep sICH and CMBs (2\% per year). ${ }^{656}$

In patients with a history of IS or transient ischaemic attack (TIA), while the presence of CMBs triples the risk of future sICH independently from other confounders, it also increases the risk of IS recurrence by $20 \% .{ }^{56}$ However, we should keep in mind the limits of relative risk comparison since the annual absolute risk of IS is much higher than the absolute risk of sICH. 
Table 1 CMBs and different antithrombotic regimens; data from randomised trials

\begin{tabular}{|c|c|c|c|c|c|c|}
\hline Study, year & Population, $\mathrm{n}$ & $\begin{array}{l}\text { Proportion baseline } \\
\text { CMBs }\end{array}$ & $\begin{array}{l}\text { Incident CMB } \\
\text { (experimental arm) }\end{array}$ & $\begin{array}{l}\text { Incident CMB } \\
\text { (control arm) }\end{array}$ & $\begin{array}{l}\text { Duration of } \\
\text { follow-up }\end{array}$ & Statistics \\
\hline CASISP ${ }^{101}$ & Non-cardioembolic IS, $\mathrm{n}=602$ & $39 \%$ & $\begin{array}{l}\text { Cilostazol } \\
5.82 \%(17 / 292)\end{array}$ & $\begin{array}{l}\text { Aspirin } \\
5.48 \%(17 / 310)\end{array}$ & 12-18 months & Non-significant \\
\hline PERFORM-MRIO0 ${ }^{102}$ & IS and $T I A, n=746$ & $35 \%$ & $\begin{array}{l}\text { Terutroban } \\
16.3 \%(59 / 362)\end{array}$ & $\begin{array}{l}\text { Aspirin } \\
10.7 \%(41 / 384)\end{array}$ & 24 months & Non-significant \\
\hline CHANCE $^{106}$ & $\begin{array}{l}\text { Minor acute IS/high-risk TIA, } \\
n=129\end{array}$ & $53 \%$ & $\begin{array}{l}\text { Aspirin/clopidogrel } \\
31 \%(21 / 68)\end{array}$ & $\begin{array}{l}\text { Aspirin } \\
28 \%(17 / 61)\end{array}$ & 90 days & OR $1.16(95 \%$ Cl 0.54 to 2.47$), p=0.71$ \\
\hline AVERROES-MRI00 ${ }^{103}$ & Atrial fibrillation, $\mathrm{n}=711$ & $10.5 \%$ & $\begin{array}{l}\text { Apixaban 5/2.5 mg } \\
7.0 \%(26 / 377)\end{array}$ & $\begin{array}{l}\text { Aspirin } \\
7.2 \%(24 / 334)\end{array}$ & 12 months & $0.92(0.53-1.60)$ \\
\hline COMPASS-MIND ${ }^{105}$ & $\begin{array}{l}\text { Advanced systemic } \\
\text { atherosclerotic disease, } \\
n=1445\end{array}$ & $30.3 \%$ & $\begin{array}{l}\text { Rivaroxaban } 2.5 \mathrm{mg} \text { twice } \\
\text { daily/aspirin } 7.5 \% \text { (36/481) } \\
\text { Rivaroxaban } 5 \mathrm{mg} \text { twice daily } \\
7.1 \% \text { (34/477) }\end{array}$ & $\begin{array}{l}\text { Aspirin } \\
5.1 \%(25 / 487)\end{array}$ & 24 months & $\begin{array}{l}\text { Rivaroxaban } 2.5 \mathrm{mg} \text { /aspirin versus } \\
\text { aspirin } 1.49(0.88-2.52), \mathrm{p}=0.141 \\
\text { Rivaroxaban } 5 \mathrm{mg} \text { versus aspirin } \\
1.40(0.82-2.39), \mathrm{p}=0.215\end{array}$ \\
\hline NAVIGATE-MIND, unpublished & ESUS, $n=728$ & $32 \%$ & $\begin{array}{l}\text { Rivaroxaban } 15 \mathrm{mg} \text { once daily } \\
\sim 7 \%\end{array}$ & $\begin{array}{l}\text { Aspirin } \\
\sim 7 \%\end{array}$ & 11 months & $0.93(0.52-1.64)$ \\
\hline \multicolumn{7}{|c|}{ Interactions between antithrombotic regimens and baseline CMBs for clinical outcomes } \\
\hline Study, year & Population, $\mathbf{n}$ & $\begin{array}{l}\text { Proportion baseline } \\
\text { CMBs }\end{array}$ & Treatment strategies & Clinical outcome & $\begin{array}{l}\text { Duration of } \\
\text { follow-up }\end{array}$ & $\begin{array}{l}\text { Interaction between CMBs and } \\
\text { treatments }\end{array}$ \\
\hline SPS3 Trial ${ }^{107}$ & Lacunar infarcts, $n=1278$ & $30 \%$ & $\begin{array}{l}\text { Aspirin/clopidogrel versus } \\
\text { aspirin alone }\end{array}$ & Stroke recurrence & 3.3 years & $\begin{array}{l}\text { No } \\
P_{\text {interaction }}=0.45\end{array}$ \\
\hline RESTART Trial MRI substudy ${ }^{109}$ & $\mathrm{ICH}, \mathrm{n}=254$ & $93 \%$ & $\begin{array}{l}\text { Antiplatelet therapy versus no } \\
\text { antithrombotic therapy }\end{array}$ & Recurrent ICH & 2 years & $\begin{array}{l}\text { No } \\
P_{\text {interaction }}=0.41,0.75,0.85 \text { for } \mathrm{CMBs} \\
\text { presence, number and location }\end{array}$ \\
\hline PICASSO Trial ${ }^{110}$ & $\begin{array}{l}\text { IS and past history of ICH or } \\
\geq 2 \mathrm{CMBs}, \mathrm{n}=1512\end{array}$ & $60 \%$ & Cilostazol versus aspirin & $\mathrm{ICH}$ & 1.9 years & $\begin{array}{l}\text { Yes } \\
P_{\text {interaction }}=0.011\end{array}$ \\
\hline NAVIGATE ESUS ${ }^{111}$ & ESUS, $n=3699$ & $11 \%$ & $\begin{array}{l}\text { Rivaroxaban } 15 \mathrm{mg} \text { once daily } \\
\text { versus aspirin }\end{array}$ & $\mathrm{ICH}$ & 11 months & $\begin{array}{l}\text { No } \\
P_{\text {interaction }}=0.97\end{array}$ \\
\hline
\end{tabular}

CMB, cerebral microbleed; ESUS, embolic stroke of undetermined source; ICH, intracerebral haemorrhage; IS, ischaemic stroke; TIA, transient ischaemic attack.

CMBs should be considered as a marker of the severity of the underlying small vessels injuries rather than a specific marker of only future haemorrhagic risk. This double-edged sword gives rise to many clinical dilemmas especially around antithrombotic therapy.

\section{CMBs and cognition}

CMBs used to be considered silent, however, they are increasingly recognised as covert lesions. ${ }^{67}$ To what extent they contribute to cognitive impairment and dementia remains unclear. Two hypothetical mechanisms (that are not exclusive) are usually discussed: CMBs may have a direct lesional effect by disrupting strategic networks, ${ }^{6869}$ or their impact on cognition may be the consequence of the underlying diffuse microangiopathy-deep perforating vasculopathy or CAA. ${ }^{70}$ Growing experimental data suggest that single or disseminated CMBs may be responsible for cognitive decline in rats and mice. ${ }^{33} 347172$

In humans, capturing the clinical and aetiological complexity of cognitive impairment caused by heterogeneous cerebrovascular lesions (eg, white matter hyperintensities, lacunar infarcts, microinfarcts, large infarcts, cortical superficial siderosis) is a methodological challenge. ${ }^{73}$ In community-dwelling registries, data on CMBs are conflicting, with some studies showing they are independent predictors of cognitive impairment while others found that the associations with cognition disappears when other vascular brain injury markers such as white matter hyperintensities and infarcts are controlled for. In a systematic review including 8736 participants, CMBs were not associated with risk of incident dementia (OR 1.14; 95\% CI 0.9 to 1.41 ), nor with risk of Alzheimer's disease (HR 1.18; 95\% CI 0.73 to 1.89). The lack of association in some studies may reflect that most individuals had a small number of CMBs, which therefore represent a modest contribution to overall disease burden. This does not preclude any effect of CMBs on dementia risk in a subset of high-risk individuals with more extensive or rapidly progressing lesions. ${ }^{67}$ In line with this hypothesis, some population-based studies reported that dementia risk was significantly increased in individuals with three or more CMBs. ${ }^{74}$

The relationship between CMBs and Alzheimer's disease is intriguing. One patient with Alzheimer's disease out of five has CMBs. ${ }^{75}$ Their anatomical distribution tends to be corticosubcortical with a posterior predominance. The high prevalence of CMBs in Alzheimer's disease can be explained by the presence of CAA and hypertension which play a role in the pathophysiology of the disease. In this context, CMBs could be a link between the amyloid cascade hypothesis and the neurovascular contribution to $\mathrm{AD} .{ }^{76}$ The presence of CMBs and the quantity of lesions may have prognostic significance and affect cognitive profile. ${ }^{77}$ However, whether detection of CMBs translates into a clinically meaningful difference remains debatable. ${ }^{78}$

\section{CMBs are not specific to cerebrovascular diseases or dementia}

CMBs have been reported in a wide variety of diseases (see table 1 in the online supplemental file 1 ).

Traumatic brain injury

Patients with traumatic brain injury frequently show punctate hypointensities visible on blood-sensitive sequences. ${ }^{79} 80$ Traumatic CMBs (also known as haemorrhagic diffuse axonal injury in this context) are associated with the severity of the injury, being a frequent finding especially in moderate-to-severe traumatic brain injury patients. ${ }^{81} 82$ However, a recent study described traumatic CMBs in approximately $30 \%$ of patients with mild traumatic brain injury. ${ }^{79} \mathrm{CMBs}$ are consistently associated with poor clinical outcome, doubling the risk of disability at 1 month and 3 months after the injury. ${ }^{79}$ Traumatic CMBs are typically located in the corpus callosum and at the grey-white matter junction, and in general have a more radial and linear 
Table 2 Research perspectives

\begin{tabular}{lll}
\hline Areas for future research & Challenges & Harmonising imaging parameters across research studies to improve cross-study \\
comparisons in line with the HARNESS initiative ${ }^{* 128}$
\end{tabular}

*HARNESS: HARmoNizing Brain Imaging MEthodS for VaScular Contributions to Neurodegeneration.

$\mathrm{CMB}$, cerebral microbleed; RCT, randomised controlled trial; SVD, small vessel disease.

configuration following the perivascular spaces compared with the rounded CMBs that are usually associated with SVD. ${ }^{83} \mathrm{~A}$ combined in vivo MRI-ex vivo MRI-histopathology study found iron-laden macrophages in the perivascular space surrounding injured vasculature, suggesting that traumatic $\mathrm{CMBs}$ are a marker of traumatic vascular injury. ${ }^{79}$

\section{Radiation induced}

Ionising radiation therapy can cause vascular and parenchymal brain damage leading to CMBs, cavernomas, white matter disease and cerebral atrophy. Chronic radiation-induced endothelial damage leads to fibrinoid necrosis, vessel wall thickening, increased permeability and thrombosis. CMBs as markers of radiation-induced SVD are commonly seen following radiation therapy of paediatric brain tumours and occur in adults. Approximately $50 \%$ of children who have undergone cranial radiation treatment develop CMBs. ${ }^{84}$ In a cohort of patients with medulloblastoma, CMBs were identified in up to $67 \%$ of patients with a median latency of 2.8 years during follow-up. ${ }^{85}$ Young age at time of cranial irradiation is a critical risk factor for the development of CMBs. ${ }^{86}$ Radiation-induced CMBs have a preferential lobar distribution, and occur particularly in occipital lobes. ${ }^{86}$

\section{Infective endocarditis}

Occult cerebral lesions, in particular CMBs and acute ischaemic lesions, are frequent in infective endocarditis. In a prospective cohort of 130 patients with infective endocarditis who underwent a brain MRI before any surgical intervention, acute ischaemic lesions were observed in 52\% and CMBs in 56\%. These observations led to a modification in diagnosis and management in nearly one patient out of five. ${ }^{87}$ In a large cohort of neurologically asymptomatic patients, CMBs were present in $57 \%$ and the majority were located in cortical areas $(85 \%) .{ }^{88}$ In the context of infective endocarditis, CMBs predict occurrence of intracranial haemorrhage, suggesting an increased vascular vulnerability. ${ }^{89}$ They might reflect blood-brain barrier disruption at the corticopial junction secondary to subacute inflammatory microvascular process or a pyogenic vasculitis. However, in this context, CMBs could also represent microemboli with an artery-to-artery embolic mechanism.

\section{Critical medical conditions}

In critically ill patients, a number of medical conditions have been associated with the presence of CMBs. In this context, CMBs usually diffusely involve the juxtacortical white matter and corpus callosum and spare the deep and periventricular white matter and the grey matter. ${ }^{90}$ Some authors suggest that in critically ill patients with respiratory failure one possible mechanism for CMB formation is hypoxaemia which might induce hydrostatic or chemical effects on the blood-brain barrier potentially leading to extravasation of erythrocytes. ${ }^{90}$ In line with this evidence, CMBs have also been reported with a similar spatial pattern in critically ill patients with COVID-19. ${ }^{91}$ Other critical medical conditions associated with the presence of CMBs are extracorporeal membrane oxygenation ${ }^{92}$ and sepsis. ${ }^{93}$ Although one can't rule out the existence of a chronic ongoing SVD in critically ill patients, these conditions should be considered as contributors to the formation of CMBs.

\section{CMBS: USEFUL BIOMARKERS IN THE ERA OF PRECISION MEDICINE?}

Management of antithrombotic agents

The heightened risk of sICH marked by $\mathrm{CMBs}$ has raised concerns regarding antithrombotic treatment in patients with thromboembolic/vaso-occlusive diseases who have CMBs on MRI. Observational data have consistently reported greater rates of future sICH in antithrombotic users with CMBs compared with those without CMBs. ${ }^{5794-97}$ Antithrombotic use has additionally been associated with prevalent CMBs in populationbased studies. ${ }^{5198}$ For instance, in cross-sectional analyses of the Rotterdam Scan Study, antiplatelet and vitamin K antagonist (VKA) users were reported to have a $1.7-$ fold $^{98}$ and 1.3 -fold ${ }^{51}$ increased risk of prevalent CMBs, respectively.

Although an association between incident CMBs and antiplatelet therapy has been reported in patients with $\mathrm{sICH},{ }^{55}$ this has not been consistently reported with anticoagulant therapy (either with VKA or non-vitamin $\mathrm{K}$ antagonist oral anticoagulants (NOACs)). 5199100 These inconsistencies reflect methodological limitations imposed by the observational design of these studies, as well as the heterogeneity in study populations.

Several MRI subgroup analyses of randomised controlled trials (RCTs) have investigated the association between differing antithrombotic regimens and the formation of new CMBs over time in non-sICH populations. These are summarised in table 1 . These trials have reported estimated annualised incident $\mathrm{CMB}$ rates of $3 \%-7 \%$, without any apparent differences when comparing between differing antiplatelet monotherapy agents, dual antiplatelet therapy versus monotherapy, or NOAC treatment versus aspirin monotherapy. ${ }^{101-106}$

Four RCTs have assessed interactions between differing antithrombotic regimens and baseline CMBs for clinical outcomes (table 1). In patients with recent lacunar stroke participating in 
the SPS3 Trial ( $n=1278$, 30\% with CMBs) there were no significant interactions noted between baseline $\mathrm{CMB}$ presence and random assignment to combined aspirin/clopidogrel treatment compared with aspirin monotherapy for the outcomes of recurrent stroke and mortality over 3.3 years of follow-up. ${ }^{107}$ The RESTART Trial recently reported a 35\% relative risk reduction in the composite (secondary) outcome of non-fatal myocardial infarction, non-fatal stroke and vascular death $(\mathrm{p}=0.025)$ in patients with sICH with concomitant thromboembolic/occlusive diseases who were randomised to antiplatelet therapy compared with no antithrombotic therapy, without potential for a meaningful increase in the primary outcome of recurrent $\mathrm{sICH}$ (adjusted HR $0.51 ; 95 \%$ CI 0.25 to 1.03$).{ }^{108}$ In the subgroup analyses of the 235 participants with CMBs from the RESTART Trial, neither the presence, burden or the location of CMBs influenced the effects of antiplatelet therapy on recurrent sICH. ${ }^{109}$

Interestingly in the PICASSO Trial, the risk of sICH was lower with cilostazol than aspirin $(0.12 \% /$ year vs $1.49 \%$ /year; HR, 0.08 ; $95 \%$ CI 0.01 to 0.60 ) in participants with IS and baseline CMBs, but was not different between the two treatment arms (1.26\%/year vs $0.79 \%$ year; HR $1.60 ; 95 \%$ CI 0.52 to $4.90)$ in participants with prior sICH $\left(p_{\text {interaction }}=0.011\right) .{ }^{110}$ These preliminary observations require validation in a confirmatory trial. With regard to anticoagulation, there were no interactions identified between baseline presence, location or severity of $\mathrm{CMBs}$ and rivaroxaban $15 \mathrm{mg}$ daily compared with aspirin for the outcomes of IS, ICH or mortality over 11 months of follow-up in NAVIGATE ESUS participants $(n=3699,11 \%$ with CMBs). ${ }^{111}$ In particular, there was no suggestion of a treatment effect for the outcome of sICH (participants with CMBs: HR $3.1,95 \%$ CI 0.3 to 30.0 ; without CMBs: HR 3.0, 95\% CI 0.6 to 14.7; interaction $\mathrm{p}=0.97$ ).

The totality of the literature to date indicates that CMBs can serve as prognostic markers for heightened sICH risk in patients with cerebrovascular disease, but their presence does not seem to modify the effect of antithrombotic therapy on clinical outcomes. Hence, their use in guiding antithrombotic therapy decision making remains questionable. The net benefit analysis of antithrombotic treatment in patients with CMBs needs to also incorporate the future risk of ischaemic events. In fact, absolute rates of IS are reported to overshadow the absolute rates of sICH in IS/TIA populations, irrespective of the baseline severity of $\mathrm{CMB}$ burden or patterns suggestive of CAA pathology. ${ }^{56} 57$ It is particularly important to keep in mind that in the context of atrial fibrillation, rates of IS stratified by CMB severity and location that are reported in anticoagulated cohorts, ${ }^{5797}$ are estimated to be $\sim$ threefold higher, should these patients be withheld anticoagulation. It has even been estimated that patients with IS/TIA with atrial fibrillation and CMBs may have greater net benefit from anticoagulant therapy than patients without CMBs, due to their much higher absolute IS rates. ${ }^{112}$ As CMBs mark a heightened risk of both ischaemic and haemorrhagic events, and the absolute rates of ischaemic events are much greater than haemorrhagic ones in non-sICH populations, the utility of incorporating them into risk scores (such as the HAS-BLED or HEMORR2HAGES) is then questionable and depends on the intended purpose of the scale. CMBs can provide additional insights when it comes to natural history and prognostication of future vascular events, and could influence more aggressive treatment of risk factors such as hypertension. However, the stroke community needs to exercise considerable caution to ensure that these emerging risk scores are not used to dissuade antithrombotic treatments, particularly in already undertreated populations such as atrial fibrillation. Current evidence does not justify withholding these evidence-based treatments from patients who had a stroke solely on the basis of CMBs on MRI. Whether the presence of CMBs can modify the effect of anticoagulation in sICH survivors with atrial fibrillation towards net harm has yet to be assessed in RCTs and remains uncertain. MRI substudies of several ongoing trials will ultimately provide more insights in this regard. ${ }^{113}$

\section{Reperfusion therapies for acute IS and CMBs}

The majority of patients enrolled in RCTs of intravenous thrombolysis (IVT) for acute IS did not undergo MRI before randomisation and therefore their $\mathrm{CMB}$ burden is unknown. In a meta-analysis of nine observational studies evaluating the safety of IVT for acute IS, the presence of at least one CMB was observed on pretreatment MRI in 23.4\% (581/2479) of included patients, and was associated with a twofold increased risk of symptomatic ICH. ${ }^{114}$ Of note, the incidence rate of symptomatic ICH was not excessively increased in patients with $\geq 1 \mathrm{CMBs}$, $(6.5 \%, 95 \%$ CI $4.8 \%$ to $8.9 \%)$ compared with patients without CMBs (4.4\%, 95\% CI 3.5\% to $5.4 \%) .{ }^{114}$ However, in the very small subgroup of 15 patients $(0.8 \%$ of included subjected) with $>10 \mathrm{CMBs}$, symptomatic ICH incidence was disproportionately high reaching $46.9 \%$ (95\% CI $22.8 \%$ to $72.5 \%) .{ }^{114}$ The former observations were reproduced in an individual patient data meta-analysis of 1973 patients with acute IS receiving IVT that reported the presence of $\geq 1$ and $>10$ CMBs in 526 $(26.7 \%)$ and $35(1.8 \%)$ patients, respectively. ${ }^{115}$ The association between $\mathrm{CMB}$ presence $(\geq 1)$ and symptomatic $\mathrm{ICH}$ failed to reach statistical significance (adjusted OR $(\mathrm{aOR})=1.42,95 \% \mathrm{CI}$ 0.86 to 2.35 ), but a count of $>10 \mathrm{CMBs}$ was strongly related to increased odds of symptomatic ICH $(\mathrm{aOR}=3.65,95 \%$ CI 1.17 to 11.42 ), remote parenchymal haemorrhage $(\mathrm{aOR}=9.09,95 \%$ CI 3.25 to 25.40 ) and poor functional outcome (adjusted OR $3.99,95 \%$ CI 1.55 to 10.22$).^{115}$

Interestingly, a recent study using a multistep algorithm populated with data from clinical studies to estimate 3 -month clinical and imaging outcomes in patients with acute IS with high CMB burden $(>10 \mathrm{CMBs})$ treated with IVT reported the following findings: (A) the beneficial treatment effect of IVT on 3-month functional outcome was attenuated in patients with $>10 \mathrm{CMBs}$ compared with patients with $\leq 10 \mathrm{CMB}$ on pretreatment brain MRI; (B) IVT was related to an increased risk of mortality in patients with $>10 \mathrm{CMBs}$; (C) IVT might be related to net harm in subgroups of patients with $>10 \mathrm{CMBs}$ defined by age, stroke symptom severity and treatment delay; nevertheless, (d) Routine pretreatment MRI to quantify CMB burden before IVT cannot generally be recommended, as long as it causes even a small additional treatment delay given the low general pretest probability of $>10$ CMBs $(0.6 \%-2.7 \%) .{ }^{116}$ However, these inferences derived from observational data need to be treated cautiously. CMBs should be factored into a holistic individual-based riskbenefit analysis to determine treatment suitability, rather than serve as go/no-go criteria of themselves. The current American Heart Association guidelines for acute IS management advocate the following recommendations: (A) In otherwise eligible patients who have had a previously demonstrated small number (1-10) of CMBs on MRI, IVT administration is reasonable (class of recommendation IIa; level of evidence $\mathrm{B}$, non-randomised); (B) In otherwise eligible patients who have had a previously demonstrated high burden of CMBs $(>10)$ on MRI, IVT may be associated with an increased risk of sICH, and the benefits of treatment are uncertain (class of recommendation IIb; level of evidence B, non-randomised); (C) Routine use of brain MRI to 
exclude CMBs before IVT is not recommended (class of recommendation III; level of evidence B, non-randomised). ${ }^{117}$

There are limited observational data indicating that CMB presence on pretreatment brain MRI is not associated with increased risk of symptomatic ICH and adverse functional outcomes in acute IS due to large vessel occlusion receiving mechanical thrombectomy with or without IVT pretreatment. ${ }^{118119}$ A recent meta-analysis including 598 patients with large vessel occlusion treated with endovascular reperfusion therapy reported that the pooled relative risk of $\mathrm{ICH}$ was 0.90 (95\% CI 0.65 to 1.25 ) in patients with CMBs (18\% of included patients) versus those without CMBs. ${ }^{120}$ In view of these considerations, it is recommended that CMB presence or burden should not represent an exclusion criterion for mechanical thrombectomy in patients with large vessel occlusion.

\section{Lipid-lowering therapies and CMBs}

Although statins have established safety and efficacy in primary and secondary stroke prevention, concerns arose about a possible increased risk of sICH. ${ }^{121}$ Independent of their cholesterollowering properties, ${ }^{122}$ pleiotropic effects of statins on coagulation and fibrinolysis have been discussed. ${ }^{123}$ However, data from clinical studies remain conflicting. A brain MRI substudy of an RCT documented that there were no statistically significant differences in the risk of incident CMBs between the rosuvastatin and placebo groups, while no significant interactions were detected between rosuvastatin use and APOE $\varepsilon 4$ status regarding new CMBs. ${ }^{124}$ Similarly, statin pretreatment was not associated with $\mathrm{CMB}$ presence among patients who had an acute cardioembolic stroke who were anticoagulation-naïve. ${ }^{125}$ Finally, there are conflicting data regarding the potential association of statin pretreatment with $\mathrm{CMB}$ presence or burden in patients with acute ICH (spontaneous ${ }^{126}$ or anticoagulation-associated ${ }^{127}$ ). In view of the former associations, $\mathrm{CMB}$ presence or high burden on brain MRI should not be used to withhold statin therapy for otherwise eligible patients in the settings of primary and secondary stroke prevention. Lastly, there are scarce if any available data regarding the potential association of other lipidlowering therapies (eg, fibrates, proprotein convertase subtilisin/ kexin type 9 inhibitors) with incident $\mathrm{sICH}$ in patients with CMBs on baseline MRI.

\section{CONCLUSION}

Huge efforts have been made to better understand the meanings of CMBs over the last decades but important issues remain to be clarified in the future (table 2). CMBs are important markers of the nature of the ongoing microangiopathy and they highlight the fact that microangiopathies are not exclusively occlusive disease. The practical clinical value for their detection has yet to be further established. To date, they are not essential to tailor our therapeutic decisions but they provide precious insights for prognostication of future vascular events. In future trials targeting SVD progression, they also could be valuable biomarkers.

\section{Twitter Laurent Puy @Lau_Puy}

Contributors PL, MP, MR, SJVV, GT, AS and CC contributed to the conception and structure of the review, drafted the text and prepared the figures.

Funding The authors have not declared a specific grant for this research from any funding agency in the public, commercial or not-for-profit sectors.

Competing interests AS reports grants and personal fees from Daiichi Sankyo Inc., grants and personal fees from Bayer AG, grants and personal fees from Servier Canada Inc., grants from Bristol-Myers Squibb, outside the submitted work; CC reports grants and personal fees from Boehringer-Ingelheim (speaker fees), BMS (steering committee), French ministry of health (grant A3ICH trial).
Patient consent for publication Not required.

Provenance and peer review Commissioned; externally peer reviewed.

Supplemental material This content has been supplied by the author(s). It has not been vetted by BMJ Publishing Group Limited (BMJ) and may not have been peer-reviewed. Any opinions or recommendations discussed are solely those of the author(s) and are not endorsed by BMJ. BMJ disclaims all liability and responsibility arising from any reliance placed on the content. Where the content includes any translated material, BMJ does not warrant the accuracy and reliability of the translations (including but not limited to local regulations, clinical guidelines, terminology, drug names and drug dosages), and is not responsible for any error and/or omissions arising from translation and adaptation or otherwise.

\section{ORCID iDs}

Laurent Puy http://orcid.org/0000-0002-9772-5192

Mark Rodrigues http://orcid.org/0000-0002-4507-6872

Georgios Tsivgoulis http://orcid.org/0000-0002-0640-3797

\section{REFERENCES}

1 Fazekas F, Kleinert R, Roob G, et al. Histopathologic analysis of foci of signal loss on gradient-echo $\mathrm{T} 2{ }^{*}$-weighted $\mathrm{Mr}$ images in patients with spontaneous intracerebral hemorrhage: evidence of microangiopathy-related microbleeds. AJNR Am J Neuroradiol 1999;20:637-42.

2 Greenberg SM, Vernooij MW, Cordonnier C, et al. Cerebral microbleeds: a guide to detection and interpretation. Lancet Neuro/ 2009:8:165-74.

3 Wardlaw JM, Smith EE, Biessels GJ, et al. Neuroimaging standards for research into small vessel disease and its contribution to ageing and neurodegeneration. Lancet Neurol 2013;12:822-38.

4 De Guio F, Jouvent E, Biessels GJ, et al. Reproducibility and variability of quantitative magnetic resonance imaging markers in cerebral small vessel disease. J Cereb Blood Flow Metab 2016:36:1319-37.

5 Nandigam RNK, Viswanathan A, Delgado P, et al. Mr imaging detection of cerebral microbleeds: effect of susceptibility-weighted imaging, section thickness, and field strength. AJNR Am J Neuroradiol 2009;30:338-43.

6 Conijn MMA, Geerlings MI, Biessels G-J, et al. Cerebral microbleeds on MR imaging: comparison between 1.5 and 7T. AJNR Am J Neuroradiol 2011;32:1043-9.

7 Bian W, Hess CP, Chang SM, et al. Susceptibility-Weighted MR imaging of radiation therapy-induced cerebral microbleeds in patients with glioma: a comparison between 3T and 7T. Neuroradiology 2014;56:91-6.

8 Stehling $\mathrm{C}$, Wersching $\mathrm{H}$, Kloska SP, et al. Detection of asymptomatic cerebral microbleeds: a comparative study at 1.5 and 3.0 T. Acad Radiol 2008;15:895-900.

9 Shams S, Martola J, Cavallin L, et al. Swi or T2*: which MRI sequence to use in the detection of cerebral microbleeds? the Karolinska imaging dementia study. AJNR Am J Neuroradiol 2015:36:1089-95.

10 Conklin J, Longo MGF, Cauley SF, et al. Validation of highly accelerated Wave-CAIPI SWI compared with conventional SWI and $T 2^{*}$-weighted gradient Recalled-Echo for routine clinical brain MRI at 3T. AJNR Am J Neuroradiol 2019:40:2073-80.

11 Gregoire SM, Chaudhary UJ, Brown MM, et al. The microbleed anatomical rating scale (MARS): reliability of a tool to map brain microbleeds. Neurology 2009;73:1759-66.

12 Cordonnier C, Potter GM, Jackson CA, et al. Improving interrater agreement about brain microbleeds: development of the brain observer microbleed scale (bombs). Stroke 2009:40:94-9.

13 Seghier ML, Kolanko MA, Leff AP, et al. Microbleed detection using automated segmentation (MIDAS): a new method applicable to standard clinical Mr images. PLoS One 2011;6:e17547.

14 Barnes SRS, Haacke EM, Ayaz M, et al. Semiautomated detection of cerebral microbleeds in magnetic resonance images. Magn Reson Imaging 2011;29:844-52.

15 van den Heuvel TLA, van der Eerden AW, Manniesing R, et al. Automated detection of cerebral microbleeds in patients with traumatic brain injury. Neuroimage Clin 2016;12:241-51

16 Liu S, Utriainen D, Chai C, et al. Cerebral microbleed detection using susceptibility weighted imaging and deep learning. Neuroimage 2019;198:271-82.

17 Haacke EM, Liu S, Buch S, et al. Quantitative susceptibility mapping: current status and future directions. Magn Reson Imaging 2015;33:1-25.

18 Liu T, Surapaneni K, Lou M, et al. Cerebral microbleeds: burden assessment by using quantitative susceptibility mapping. Radiology 2012;262:269-78.

19 Shoamanesh A, Kwok CS, Benavente O. Cerebral microbleeds: histopathological correlation of neuroimaging. Cerebrovasc Dis 2011;32:528-34

20 van Veluw SJ, Biessels GJ, Klijn CJM, et al. Heterogeneous histopathology of cortical microbleeds in cerebral amyloid angiopathy. Neurology 2016;86:867-71.

21 van Veluw SJ, Charidimou A, van der Kouwe AJ, et al. Microbleed and microinfarct detection in amyloid angiopathy: a high-resolution MRI-histopathology study. Brain 2016;139:3151-62.

22 Schrag M, McAuley G, Pomakian J, et al. Correlation of hypointensities in susceptibility-weighted images to tissue histology in dementia patients with 
cerebral amyloid angiopathy: a postmortem MRI study. Acta Neuropathol 2010;119:291-302.

23 Haller S, Montandon M-L, Lazeyras F, et al. Radiologic-Histopathologic correlation of cerebral microbleeds using Pre-Mortem and post-mortem MRI. PLoS One 2016;11:e0167743.

24 Haller S, Scheffler M, Salomir R, et al. Mri detection of cerebral microbleeds: size matters. Neuroradiology 2019;61:1209-13.

25 Veluw SJ, Scherlek AA, Freeze WM, et al. Different microvascular alterations underlie microbleeds and microinfarcts. Ann Neurol 2019;86:279-92.

26 Freeze WM, Bacskai BJ, Frosch MP, et al. Blood-Brain barrier leakage and microvascular lesions in cerebral amyloid angiopathy. Stroke 2019;50:328-35.

27 Sperling RA, Jack CR, Black SE, et al. Amyloid-Related imaging abnormalities in amyloid-modifying therapeutic trials: recommendations from the Alzheimer's association research roundtable Workgroup. Alzheimers Dement 2011;7:367-85.

28 Guidoux C, Hauw J-J, Klein IF, et al. Amyloid angiopathy in brain hemorrhage: a postmortem Neuropathological-Magnetic resonance imaging study. Cerebrovasc Dis 2018;45:124-31.

29 Janaway BM, Simpson JE, Hoggard N, et al. Brain haemosiderin in older people: pathological evidence for an ischaemic origin of magnetic resonance imaging (MRI) microbleeds. Neuropathol Appl Neurobiol 2014;40:258-69.

30 Cianchetti FA, Kim DH, Dimiduk S, et al. Stimulus-Evoked calcium transients in somatosensory cortex are temporarily inhibited by a nearby microhemorrhage. PLOS One 2013;8:e65663.

31 Rosidi NL, Zhou J, Pattanaik S, et al. Cortical microhemorrhages cause local inflammation but do not trigger widespread dendrite degeneration. PLoS One 2011;6:e26612.

32 Ahn SJ, Anrather J, Nishimura N, et al. Diverse inflammatory response after cerebral microbleeds includes coordinated microglial migration and proliferation. Stroke 2018;49:1719-26.

33 Sudduth TL, Powell DK, Smith CD, et al. Induction of hyperhomocysteinemia models vascular dementia by induction of cerebral microhemorrhages and neuroinflammation. J Cereb Blood Flow Metab 2013;33:708-15.

34 He X-F, Lan Y, Zhang Q, et al. Deferoxamine inhibits microglial activation, attenuates blood-brain barrier disruption, rescues dendritic damage, and improves spatial memory in a mouse model of microhemorrhages. J Neurochem 2016:138:436-47.

35 Mracsko E, Veltkamp R. Neuroinflammation after intracerebral hemorrhage. Front Cell Neurosci 2014:8:388.

36 Linn J, Halpin A, Demaerel P, et al. Prevalence of superficial siderosis in patients with cerebral amyloid angiopathy. Neurology 2010;74:1346-50.

37 Pasi M, Charidimou A, Boulouis G, et al. Mixed-location cerebral hemorrhage/ microbleeds: underlying microangiopathy and recurrence risk. Neurology 2018:90:e119-26.

38 Charidimou A, Pantoni L, Love S. The concept of sporadic cerebral small vesse disease: a road map on key definitions and current concepts. Int I Stroke 2016;11:6-18.

39 Martinez-Ramirez S, Romero J-R, Shoamanesh A, et al. Diagnostic value of lobar microbleeds in individuals without intracerebral hemorrhage. Alzheimers Dement 2015:11:1480-8.

40 Charidimou A, Frosch MP, Al-Shahi Salman R, Salman RA-S, et al. Advancing diagnostic criteria for sporadic cerebral amyloid angiopathy: study protocol for a multicenter MRI-pathology validation of Boston criteria v2.0. Int I Stroke 2019;14:956-71.

41 Schreiber S, Wilisch-Neumann A, Schreiber F, et al. Invited review: the spectrum of age-related small vessel diseases: potential overlap and interactions of amyloid and nonamyloid vasculopathies. Neuropathol App/ Neurobiol 2020;46:219-39.

42 Blanc C, Viguier A, Calviere L, et al. Underlying small vessel disease associated with mixed cerebral microbleeds. Front Neurol 2019:10:1126.

43 Chung C-P, Chen J-W, Chang F-C, et al. Cerebral microbleed burdens in specific brain regions are associated with disease severity of cerebral autosomal dominan arteriopathy with subcortical infarcts and leukoencephalopathy. J Am Heart Assoc 2020;9:e016233.

44 Pasi M, Pongpitakmetha T, Charidimou A, et al. Cerebellar microbleed distribution patterns and cerebral amyloid angiopathy. Stroke 2019;50:1727-33.

45 Tsai H-H, Pasi M, Tsai L-K, et al. Superficial cerebellar microbleeds and cerebral amyloid angiopathy: a magnetic resonance Imaging/Positron emission tomography study. Stroke 2020;51:202-8.

46 Sveinbjornsdottir S, Sigurdsson S, Aspelund T, et al. Cerebral microbleeds in the population based AGES-Reykjavik study: prevalence and location. J Neurol Neurosurg Psychiatry 2008;79:1002-6.

47 Romero JR, Preis SR, Beiser A, et al. Risk factors, stroke prevention treatments, and prevalence of cerebral microbleeds in the Framingham heart study. Stroke 2014:45:1492-4.

48 Poels MMF, Vernooij MW, Ikram MA, et al. Prevalence and risk factors of cerebral microbleeds: an update of the Rotterdam scan study. Stroke 2010;41:S103-6.

49 Akoudad S, Portegies MLP, Koudstaal PJ, et al. Cerebral microbleeds are associated with an increased risk of stroke: the Rotterdam study. Circulation 2015;132:509-16.

50 Poels MMF, Ikram MA, van der Lugt A, et al. Incidence of cerebral microbleeds in the general population: the Rotterdam scan study. Stroke 2011;42:656-61.
51 Akoudad S, Darweesh SKL, Leening MJG, et al. Use of coumarin anticoagulants and cerebral microbleeds in the general population. Stroke 2014:45:3436-9.

52 Mesker DJ, Poels MMF, Ikram MA, et al. Lobar distribution of cerebral microbleeds: the Rotterdam scan study. Arch Neurol 2011:68:656-9.

53 Cordonnier C, Al-Shahi Salman R, Wardlaw J. Spontaneous brain microbleeds: systematic review, subgroup analyses and standards for study design and reporting. Brain 2007;130:1988-2003.

54 Perry LA, Rodrigues M, Al-Shahi Salman R, et al. Incident cerebral microbleeds after intracerebral hemorrhage. Stroke 2019;50:2227-30.

55 Pasquini M, Benedictus MR, Boulouis G, et al. Incident cerebral microbleeds in a cohort of intracerebral hemorrhage. Stroke 2016;47:689-94.

56 Wilson D, Ambler G, Lee K-J, et al. Cerebral microbleeds and stroke risk after ischaemic stroke or transient ischaemic attack: a pooled analysis of individual patient data from cohort studies. Lancet Neurol 2019;18:653-65.

57 Wilson D, Ambler G, Shakeshaft C, et al. Cerebral microbleeds and intracrania haemorrhage risk in patients anticoagulated for atrial fibrillation after acute ischaemic stroke or transient ischaemic attack (CROMIS-2): a multicentre observational cohort study. Lancet Neurol 2018;17:539-47.

58 Puy L, De Guio F, Godin O, et al. Cerebral microbleeds and the risk of incident ischemic stroke in CADASIL (cerebral autosomal dominant arteriopathy with subcortical infarcts and leukoencephalopathy). Stroke 2017;48:2699-703.

59 Uemura M, Nozaki H, Kato T, et al. HTRA 1-Related cerebral small vessel disease: a review of the literature. Front Neurol 2020;11:545

60 van Rooden S, van der Grond J, van den Boom R, et al. Descriptive analysis of the Boston criteria applied to a Dutch-type cerebral amyloid angiopathy population. Stroke 2009:40:3022-7.

61 Lanfranconi S, Markus HS. Col4A1 mutations as a monogenic cause of cerebral small vessel disease: a systematic review. Stroke 2010;41:e513-8.

62 Wenz H, Wenz R, Maros M, et al. Incidence, locations, and longitudinal course of cerebral microbleeds in European moyamoya. Stroke 2017:48:307-13.

63 Kono Y, Wakabayashi T, Kobayashi M, et al. Characteristics of cerebral microbleeds in patients with Fabry disease. I Stroke Cerebrovasc Dis 2016;25:1320-5.

64 Charidimou A, Shams S, Romero JR, et al. Clinical significance of cerebral microbleeds on MRI: a comprehensive meta-analysis of risk of intracerebral hemorrhage, ischemic stroke, mortality, and dementia in cohort studies (V1). Int J Stroke 2018;13:454-68.

65 Charidimou A, Imaizumi T, Moulin S, et al. Brain hemorrhage recurrence, small vessel disease type, and cerebral microbleeds: a meta-analysis. Neurology 2017;89:820-9.

66 Imaizumi T, Inamura S, Nomura T. Contribution of deep microbleeds to stroke recurrence: differences between patients with past deep intracerebral hemorrhages and lacunar infarctions. I Stroke Cerebrovasc Dis 2015:24:1855-64.

67 Debette S, Schilling S, Duperron M-G, et al. Clinical significance of magnetic resonance imaging markers of vascular brain injury: a systematic review and metaanalysis. JAMA Neurol 2019;76:81-94.

68 Heringa SM, Reijmer YD, Leemans A, et al. Multiple microbleeds are related to cerebral network disruptions in patients with early Alzheimer's disease. J Alzheimers Dis 2014:38:211-21.

69 Werring DJ, Frazer DW, Coward LJ, et al. Cognitive dysfunction in patients with cerebral microbleeds on T2*-weighted gradient-echo MRI. Brain 2004;127:2265-75.

70 Poels MMF, Ikram MA, van der Lugt A, et al. Cerebral microbleeds are associated with worse cognitive function: the Rotterdam scan study. Neurology 2012;78:326-33

71 Barus $\mathrm{R}$, Bergeron $\mathrm{S}$, Auger $\mathrm{F}$, et al. Sex differences in cognitive impairment induced by cerebral microhemorrhage. Trans/ Stroke Res 2020. doi:10.1007/s12975-020 00820-1. [Epub ahead of print: 21 May 2020].

72 Pétrault M, Ouk T, Pétrault O, et al. Safety of oral anticoagulants on experimental brain microbleeding and cognition. Neuropharmacology 2019:155:162-72.

73 Moulin S, Cordonnier C. Role of cerebral microbleeds for intracerebral haemorrhage and dementia. Curr Neurol Neurosci Rep 2019:19:51.

74 Ding J, Sigurðsson S, Jónsson PV, et al. Space and location of cerebral microbleeds, cognitive decline, and dementia in the community. Neurology 2017;88:2089-97.

75 Sepehry AA, Lang D, Hsiung G-Y, et al. Prevalence of brain microbleeds in Alzheimer disease: a systematic review and meta-analysis on the influence of neuroimaging techniques. AJNR Am J Neuroradiol 2016:37:215-22.

76 Cordonnier C, van der Flier WM. Brain microbleeds and Alzheimer's disease: innocent observation or key player? Brain 2011:134:335-44.

77 Pettersen JA, Sathiyamoorthy G, Gao F-Q, et al. Microbleed topography, leukoaraiosis, and cognition in probable Alzheimer disease from the Sunnybrook dementia study. Arch Neurol 2008;65:790-5.

78 van der Vlies AE, Goos JDC, Barkhof F, et al. Microbleeds do not affect rate of cognitive decline in Alzheimer disease. Neurology 2012;79:763-9.

79 Griffin AD, Turtzo LC, Parikh GY, et al. Traumatic microbleeds suggest vascular injury and predict disability in traumatic brain injury. Brain 2019;142:3550-64.

80 Scheid R, Preul C, Gruber 0, et al. Diffuse axonal injury associated with chronic traumatic brain injury: evidence from $\mathrm{T}^{*}$-weighted gradient-echo imaging at $3 \mathrm{~T}$. AJNR Am J Neuroradiol 2003;24:1049-56. 
81 Babikian T, Freier MC, Tong KA, et al. Susceptibility weighted imaging: neuropsychologic outcome and pediatric head injury. Pediatr Neurol 2005;33:184-94.

82 Beauchamp MH, Beare R, Ditchfield M, et al. Susceptibility weighted imaging and its relationship to outcome after pediatric traumatic brain injury. Cortex 2013;49:591-8.

83 Chiara Ricciardi M, Bokkers RPH, Butman JA, et al. Trauma-Specific brain abnormalities in suspected mild traumatic brain injury patients identified in the first 48 hours after injury: a blinded magnetic resonance imaging comparative study including suspected acute minor stroke patients. J Neurotrauma 2017;34:23-30.

84 Roddy E, Sear K, Felton E, et al. Presence of cerebral microbleeds is associated with worse executive function in pediatric brain tumor survivors. Neuro Oncol 2016;18:iii 159.2-iii159.

85 Roongpiboonsopit D, Kuijf HJ, Charidimou A, et al. Evolution of cerebral microbleeds after cranial irradiation in medulloblastoma patients. Neurology 2017;88:789-96.

86 Lupo JM, Chuang CF, Chang SM, et al. 7-Tesla susceptibility-weighted imaging to assess the effects of radiotherapy on normal-appearing brain in patients with glioma. Int J Radiat Oncol Biol Phys 2012;82:e493-500.

87 Duval $\mathrm{X}$, lung $\mathrm{B}$, Klein I, et al. Effect of early cerebral magnetic resonance imaging on clinical decisions in infective endocarditis: a prospective study. Ann Intern Med 2010;152:W175:497-504

88 Hess A, Klein I, lung B, et al. Brain MRI findings in neurologically asymptomatic patients with infective endocarditis. AJNR Am J Neuroradiol 2013;34:1579-84.

89 Okazaki S, Sakaguchi M, Hyun B, et al. Cerebral microbleeds predict impending intracranial hemorrhage in infective endocarditis. Cerebrovasc Dis 2011;32:483-8.

90 Fanou EM, Coutinho JM, Shannon P, et al. Critical Illness-Associated cerebral microbleeds. Stroke 2017;48:1085-7.

91 Agarwal S, Jain R, Dogra S, et al. Cerebral microbleeds and leukoencephalopathy in critically ill patients with COVID-19. Stroke 2020;51:2649-55.

92 Liebeskind DS, Sanossian N, Sapo ML, et al. Cerebral microbleeds after use of extracorporeal membrane oxygenation in children. J Neuroimaging 2013;23:75-8.

93 Corrêa DG, Cruz Júnior LCH, Bahia PRV, et al. Intracerebral microbleeds in sepsis: susceptibility-weighted MR imaging findings. Arq Neuropsiquiatr 2012;70:903-4.

94 Soo YOY, Yang SR, Lam WWM, et al. Risk vs benefit of anti-thrombotic therapy in ischaemic stroke patients with cerebral microbleeds. J Neurol 2008:255:1679-86.

95 Lovelock CE, Cordonnier C, Naka H, et al. Antithrombotic drug use, cerebral microbleeds, and intracerebral hemorrhage: a systematic review of published and unpublished studies. Stroke 2010;41:1222-8.

96 Biffi A, Halpin A, Towfighi A, et al. Aspirin and recurrent intracerebral hemorrhage in cerebral amyloid angiopathy. Neurology 2010;75:693-8.

97 Martí-Fàbregas J, Medrano-Martorell S, Merino E, et al. MRI predicts intracranial hemorrhage in patients who receive long-term oral anticoagulation. Neurology 2019:92:e2432-43.

98 Vernooij MW, Haag MDM, van der Lugt A, et al. Use of antithrombotic drugs and the presence of cerebral microbleeds: the Rotterdam scan study. Arch Neurol 2009:66:714-20.

99 Soo Y, Abrigo J, Leung KT, et al. Correlation of non-vitamin K antagonist oral anticoagulant exposure and cerebral microbleeds in Chinese patients with atria fibrillation. J Neurol Neurosurg Psychiatry 2018;89:680-6.

100 Yokoyama M, Mizuma A, Terao T, et al. Effectiveness of Nonvitamin K antagonist oral anticoagulants and warfarin for preventing further cerebral microbleeds in acute ischemic stroke patients with nonvalvular atrial fibrillation and at least one microbleed: CMB-NOW multisite pilot trial. J Stroke Cerebrovasc Dis 2019;28:1918-25.

101 Huang Y, Cheng Y, Wu J, et al. Cilostazol as an alternative to aspirin after ischaemic stroke: a randomised, double-blind, pilot study. Lancet Neurol 2008;7:494-9.

102 Chabriat H, Maeder $\mathrm{P}$, Gass A, et al. Results of the perform magnetic resonance imaging study. J Neurol 2013;260:3071-6.

103 O'Donnell MJ, Eikelboom JW, Yusuf S, et al. Effect of apixaban on brain infarction and microbleeds: AVERROES-MRI assessment study. Am Heart J 2016;178:145-50.

104 Sharma M, Kasner S. Effects of rivaroxaban vs acetylsalicylic acid on the occurrence of the clinical and MRI-defined infarcts and microbleeds in NAVIGATE-ESUS results of navigate mind MRI Sub-study As03-032, 2019.

105 Sharma M, Hart RG, Smith EE, et al. Rivaroxaban for prevention of covert brain infarcts and cognitive decline: the COMPASS MRI substudy. Stroke 2020;51:2901-9.
106 Wang Z, Xu C, Wang P, et al. Combined clopidogrel-aspirin treatment for high risk TIA or minor stroke does not increase cerebral microbleeds. Neurol Res 2015;37:993-7

107 Shoamanesh A, Pearce LA, Bazan C, et al. Microbleeds in the secondary prevention of small subcortical strokes trial: stroke, mortality, and treatment interactions. Ann Neurol 2017:82:196-207.

108 Al-Shahi Salman R, Dennis MS, Sandercock PAG, et al. Effects of antiplatelet therapy after stroke due to intracerebral haemorrhage (restart): a randomised, open-label trial. Lancet 2019;393:2613-23.

109 Al-Shahi Salman R, Minks DP, Mitra D, et al. Effects of antiplatelet therapy on stroke risk by brain imaging features of intracerebral haemorrhage and cerebral small vessel diseases: subgroup analyses of the restart randomised, open-label trial. Lancet Neurol 2019;18:643-52.

110 Park H-K, Lee JS, Kim BJ, et al. Cilostazol versus aspirin in ischemic stroke with cerebral microbleeds versus prior intracerebral hemorrhage. Int J Stroke 2020;17474 93020941273:174749302094127.

111 Shoamanesh A, Hart RG, Connolly SJ, et al. Microbleeds and the effect of anticoagulation in patients with embolic stroke of undetermined source: an exploratory analysis of the navigate ESUS randomized clinical trial. JAMA Neurol 2020. doi:10.1001/jamaneurol.2020.3836. [Epub ahead of print: 19 Oct 2020]

112 Shoamanesh A, Charidimou A, Sharma M, et al. Should patients with ischemic stroke or transient ischemic attack with atrial fibrillation and microbleeds be anticoagulated? Stroke 2017:48:3408-12.

113 Shoamanesh A, Charidimou A, Sheth KN. Comorbid atrial fibrillation in cerebral amyloid angiopathy-related intracerebral hemorrhage: between a rock and a hard place. J Stroke Cerebrovasc Dis 2019;28:104351.

114 Tsivgoulis G, Zand R, Katsanos AH, et al. Risk of symptomatic intracerebral hemorrhage after intravenous thrombolysis in patients with acute ischemic stroke and high cerebral microbleed burden: a meta-analysis. JAMA Neurol 2016;73:675-83.

115 Charidimou A, Turc G, Oppenheim C, et al. Microbleeds, cerebral hemorrhage, and functional outcome after stroke thrombolysis. Stroke 2017:48:2084-90.

116 Schlemm L, Endres M, Werring DJ, et al. Benefit of intravenous thrombolysis in acute ischemic stroke patients with high cerebral microbleed burden. Stroke 2020;51:232-9.

117 Powers WJ, Rabinstein AA, Ackerson T, et al. Guidelines for the early management of patients with acute ischemic stroke: 2019 update to the 2018 guidelines for the early management of acute ischemic stroke: a guideline for healthcare professionals from the American heart Association/American stroke association. Stroke 2019:50:e344-418.

118 Soo YOY, Siu DYW, Abrigo J, et al. Risk of intracerebral hemorrhage in patients with cerebral microbleeds undergoing endovascular intervention. Stroke 2012:43:1532-6.

119 Shi Z-S, Duckwiler GR, Jahan R, et al. Mechanical thrombectomy for acute ischemic stroke with cerebral microbleeds. J Neurointerv Surg 2016;8:563-7.

120 Wu X, Yan J, Ye H, et al. Pre-treatment cerebral microbleeds and intracranial hemorrhage in patients with ischemic stroke receiving endovascular therapy: a systematic review and meta-analysis. J Neurol 2020;267:1227-32.

121 Goldstein LB, Amarenco P, Szarek M, et al. Hemorrhagic stroke in the stroke prevention by aggressive reduction in cholesterol levels study. Neurology 2008:70:2364-70.

122 Pandit AK, Kumar P, Kumar A, et al. High-dose statin therapy and risk of intracerebra hemorrhage: a meta-analysis. Acta Neurol Scand 2016:134:22-8.

123 Endres M, Nolte CH, Scheitz JF. Statin treatment in patients with intracerebral hemorrhage. Stroke 2018;49:240-6.

124 Ji T, Zhao Y, Wang J, et al. Effect of low-dose statins and apolipoprotein E genotype on cerebral small vessel disease in older hypertensive patients: a subgroup analysis of a randomized clinical trial. J Am Med Dir Assoc 2018; 19:995-1002

125 Martí-Fàbregas J, Medrano-Martorell S, Merino E, et al. Statins do not increase markers of cerebral Angiopathies in patients with cardioembolic stroke. Sci Rep 2018;8:1492.

126 Haussen DC, Henninger N, Kumar S, et al. Statin use and microbleeds in patients with spontaneous intracerebral hemorrhage. Stroke 2012:43:2677-81.

127 Lioutas V-A, Goyal N, Katsanos AH, et al. Microbleed prevalence and burden in anticoagulant-associated intracerebral bleed. Ann Clin Trans/ Neurol 2019:6:1546-51.

128 Smith EE, Biessels GJ, De Guio F, et al. Harmonizing brain magnetic resonance imaging methods for vascular contributions to neurodegeneration. Alzheimers Dement 2019;11:191-204 